\title{
Opportunistic feeding by dabs within areas of trawl disturbance: possible implications for increased survival
}

\author{
Michel J. Kaiser ${ }^{1, *}$, Kirsten Ramsay ${ }^{1,2}$ \\ ${ }^{1}$ The Centre for Environment, Fisheries and Aquaculture Science, Conwy Laboratory" ${ }^{\circ}$, Benarth Rd, Conwy LL32 8UB, United Kingdom \\ ${ }^{2}$ Ecology Group, School of Biological Sciences, Deiniol Rd, Bangor, Gwynedd LL57 2UW, United Kingdom
}

\begin{abstract}
As demersal fishing gears are towed across the seabed they dig up or damage infauna. Dab Limanda limanda L. are known to aggregate in areas disturbed by trawls. We demonstrate that dab alter their diet and increase their food intake when feeding in these areas. Although dabs are frequently caught in large numbers as part of the by-catch of commercial flatfish fisheries, and a large proportion of these die, they remain the most abundant flatfish species in the North Sea. Fisheries have selectively removed species that prey upon or compete with dab. Furthermore, fishing activity increases feeding opportunities for dabs. These factors may have contributed to the observed increase in the abundance of dab in the North Sea.
\end{abstract}

KEY WORDS: Dab . Fishing disturbance Diet Feeding behaviour Population changes

Dab Limanda limanda L. is the most abundant flatfish species in the North Sea with an estimated biomass of 2 million tonnes (Daan et al. 1990). Dab are widely distributed throughout the whole North Sea and are found at depths of up to $100 \mathrm{~m}$; however, the vast majority of the population occurs in the southeastern North Sea on shallow (<30 m) sandy substrata (Daan et al. 1990). Dab are caught as a by-catch of the plaice Pleuronectes platessa L. and sole Solea solea L. fishery in the North Sea. Their survival rate after capture in trawls is at most $24 \%$ (Kaiser \& Spencer 1995). Despite this high by-catch mortality the biomass of dab has either remained relatively constant or increased in areas of the central North Sea over the last decade (Rijnsdorp et al. 1992, Heessen \& Daan 1996). Several explanations for the stability of the dab population have been forwarded. Intensive fishing in the North

\footnotetext{
·E-mail:m.j.kaiser@cefas.co.uk

" Formerly known as The Directorate of Fisheries Research,

Fisheries Laboratory, Conwy
}

Sea since 1945 has reduced the population size of predatory fish species such as cod Gadus morhua L. which feed on dab (Daan et al. 1990, Greenstreet \& Hall 1996). Eutrophication through anthropogenic activities has led to an increase in the abundance of the brittlestar Amphiura spp. in the North Sea (Duineveld et al. 1987, Lindley et al. 1995), which are an important component in the diet of dab (Duineveld \& van Noort 1986). In undisturbed sediments Amphiura spp. are positioned with their oral discs buried within the sediment while their arms protrude from the sediment surface. Under these circumstances, dab graze the exposed arms, while leaving the oral disc intact (Duineveld \& van Noort 1986).

The passage of bottom trawls across the seabed disturbs, injures or kills a variety of epi- and infaunal animals, which are eaten by scavenging species (Kaiser \& Spencer 1994, 1996a). In the North and Irish Seas, dab are one of the first scavengers to aggregate in recently trawled areas, and consequently may gain extra food as a result of trawling activity (Kaiser \& Spencer 1996b). The benefits of extra food generated by fishing activities may, in part, outweigh the negative effects of bycatch mortality for the dab population in the North Sea.

As part of a larger study examining the ecological effects of trawling on benthic communities, we examined the possibility that dab increase their intake of food in areas of the seabed recently disturbed by fishing gears.

Methods. Our experiment was carried out at a depth of $40 \mathrm{~m}$ on a fine mud/sand sediment in the Irish Sea approximately 12 nautical miles offshore from Walney Island, Lancashire, UK. All fishing was carried out during daylight using the RV 'Carystes'. The ship's position was ascertained from a differential global positioning system (accurate to within $5 \mathrm{~m}$ ) relayed through Sextant navigational software. 
The experimental protocol was as follows: 3 parallel lines, each $250 \mathrm{~m}$ apart, were initially sampled with a relatively light beam trawl. The centre line was then fished with a heavy commercial beam trawl. All 3 lines were resampled at 3 time intervals after fishing with the commercial gear.

The commercial gear chosen for this experiment was a $4 \mathrm{~m}$ wide beam trawl rigged with a chain matrix and an $80 \mathrm{~mm}$ diamond mesh codend (Kaiser \& Spencer 1994). This gear is commonly used by an increasing fleet of beam trawlers $<300 \mathrm{hp}$ in the seas of northern Europe. The trawl was fished along the same plotted wayline (1500 $\mathrm{m}$ long) 10 times which disturbs a strip of seabed 30 to $40 \mathrm{~m}$ wide. This line was termed the 'treatment line'. The area was then left undisturbed overnight $(10 \mathrm{~h})$ to allow scavengers to aggregate on the disturbed area. A light $2.8 \mathrm{~m}$ wide beam trawl fitted with 6 tickler chains and a $4 \mathrm{~cm}$ square meshed codend was used to sample the 3 lines both before and after fishing with the commercial trawl. Although the light trawl would unavoidably create its own disturbance, the magnitude of this disturbance was considered to be much less than that caused by the commercial trawl which weighed ca 3.5 tonnes in air (cf. $400 \mathrm{~kg}$ ). Six samples were collected from both the treatment and adjacent unfished control lines using the light trawl alternating between the lines at random to avoid effects of tidal and diel variation in feeding activity. Tow duration was standardised to $15 \mathrm{~min}$ at a towing speed of 2.5 knots. Dabs from each catch were counted. Forty dabs were collected at random from each set of control and treatment samples and frozen for later analysis. This procedure was repeated at $24 \mathrm{~h}$ intervals for a further $3 \mathrm{~d}$.

In the laboratory, dabs were thawed and their total length measured $\pm 1 \mathrm{~mm}$. Stomachs were then removed, dissected and the contents washed into a watch glass. Organisms present in each stomach were sorted, counted and identified to species level when possible. When parts of organisms were prevalent these were removed and their dry weight measured after drying at $60^{\circ} \mathrm{C}$ for $24 \mathrm{~h}$. Empty bivalve shells were not included. Counts of organisms were only made when positive identification of individuals was possible, e.g. the presence of the oral disc of brittlestars.

Differences in the mean (In transformed) number of dabs caught per $1000 \mathrm{~m}^{2}$ on the control and treatment lines were compared for each day using a generalised linear model analysis of variance (ANOVA) with a multiple comparison test for the comparison of differences between pairs of control and treatment samples. The mean length of dabs collected for stomach contents analyses from the control and treatment lines were compared using a t-test. The weights of stomach contents were divided by the length of each fish to give a standardised index of food consumed per fish length $(\mathrm{SC} / \mathrm{FL})$. The data were highly skewed, hence the differences between the treatment and control lines for each day were tested using the non-parametric Kruskal-Wallis test (K-W). Experience has shown that the same ground is rarely sampled with the $2.8 \mathrm{~m}$ beam trawl, hence each sample is considered to have been collected at random. Consequently, a repeated measures procedure is inappropriate. The number of prey eaten for each sample of 40 dabs collected from the control and treatment line were compared using either a chi-squared test or a Fisher's exact test assuming an expected ratio of $1: 1$

Results. The mean density of dab was significantly lower on the treatment line for $48 \mathrm{~h}$ after it had been fished with the commercial beam trawl (Fig. 1). This contrasts with an earlier study in which Kaiser \& Spencer (1996a) reported that dab were 3 times more abundant in trawled areas for at least $48 \mathrm{~h}$ after the initial disturbance.

There were no significant differences between the mean lengths of the dab collected for stomach contents analyses from the treatment and control lines (Table 1). Prior to disturbing the seabed with the commercial trawl, the majority of stomachs of dab collected from control and treatment lines contained unidentifiable digesta (Fig. 2). Digesta was most prevelant in the stomachs of dab sampled from the control line, which resulted in a significantly greater SC/FL index for these dab (Fig. 3; K-W, $H=19.9$, p $<0.001$ ). However, this may be explained by the relatively high proportion of empty stomachs of dab collected from the treatment line (Fig. 3). The arms of Amphiura spp. occurred in a smaller proportion of stomachs prior to trawling $(<15 \%)$ (Fig. 2). Immediately after creating the trawling disturbance, none of the stomachs analysed contained digesta only, all contained identifiable, and recently consumed prey. However, the

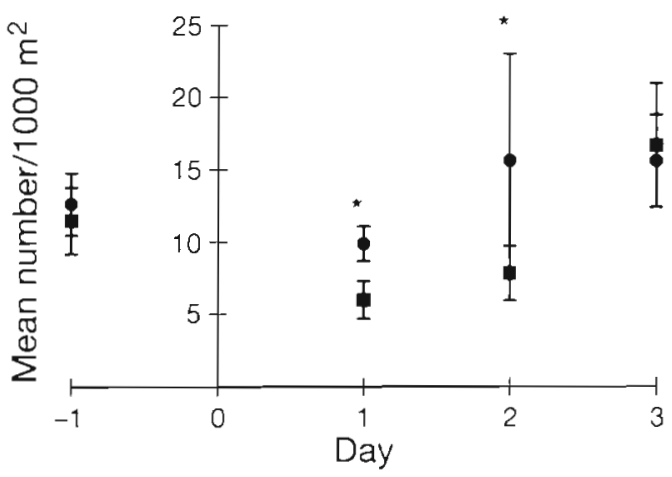

Fig. 1. Limanda limanda. Mean density ( $\pm 95 \%$ CI) of dab sampled on the treatment ( $\bullet$ ) and control $(\bullet)$ lines before $(-1)$ and at $24 \mathrm{~h}$ periods after creating the fishing disturbance ( 1 to 3$)$ * Significant differences $(p<0.05)$ 
Table 1. Limanda limanda. Mean ( $\pm \mathrm{SEM}$ ) length $(\mathrm{mm}$ ) of dab sampled for stomach contents analyses from the trawled and adjacent unfished areas on consecutive days before $(-1)$ and after (1 to 3) creating the fishing disturbance. Forty dab were sampled per treatment per day

\begin{tabular}{|c|c|c|c|c|}
\hline Day & -1 & 1 & 2 & 3 \\
\hline Treatment & $187.2 \pm 4.1$ & $195.0 \pm 2.5$ & $193.9 \pm 3.6$ & $191.1 \pm 5.2$ \\
\hline Control & $184.1 \pm 5.7$ & $195.7 \pm 2.7$ & $186.5 \pm 4.0$ & $187.0 \pm 4.9$ \\
\hline ANOVA $F_{1,78}$ & 0.15 & 0.01 & 1.03 & 0.72 \\
\hline $\mathrm{p}$ & 0.6 & 0.9 & 0.3 & 0.4 \\
\hline
\end{tabular}

composition of the stomach contents differed for dab collected from the control and treatment lines. A larger number of the stomachs of dab collected on the control lines contained Amphiura spp. arms compared with those of fish collected on the treatment line (Fig. 2; Fisher's exact test, $\mathrm{p}<0.001$ ). In contrast, the stomachs of dab collected from the treatment line contained much larger numbers of oral discs of Amphiura spp. than those collected on the control line on 3 consecutive days after the initial disturbance (Fig. $2 ; \chi^{2}=$ 228.3, p $<0.001$ ). Immediately after the fishing distur-
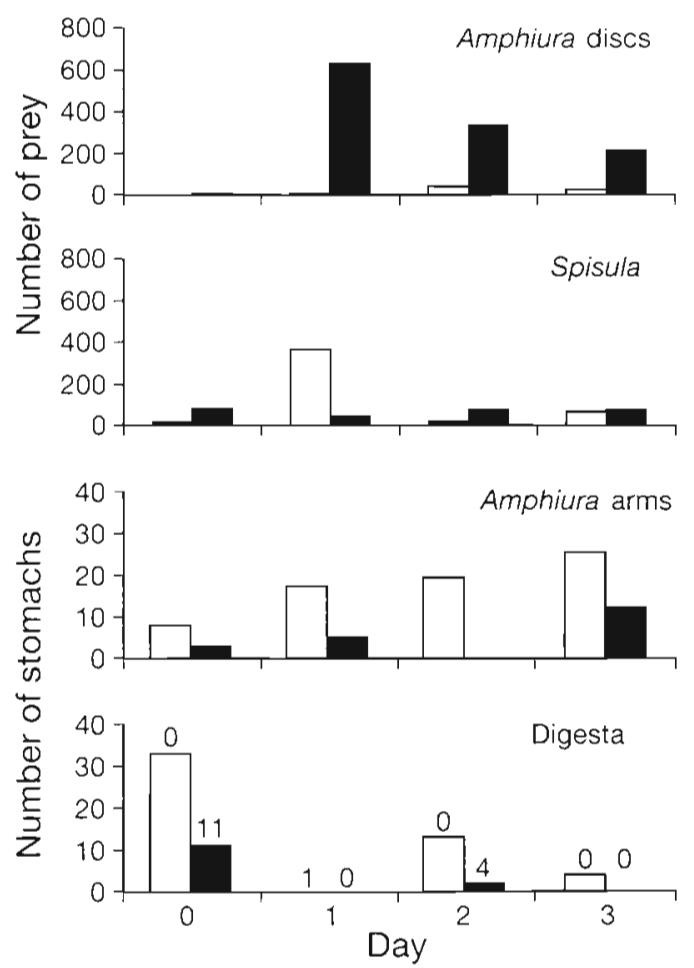

Fig. 2. Limanda limanda. Number of prey eaten or the number of stomachs containing either digesta or parts of prey for a sample ( $n=40)$ of dab from the control (white bars) or treatment lines (black bars) at time intervals before and after creating the fishing disturbance. The numbers given in the figure for digesta indicate the number of empty stomachs

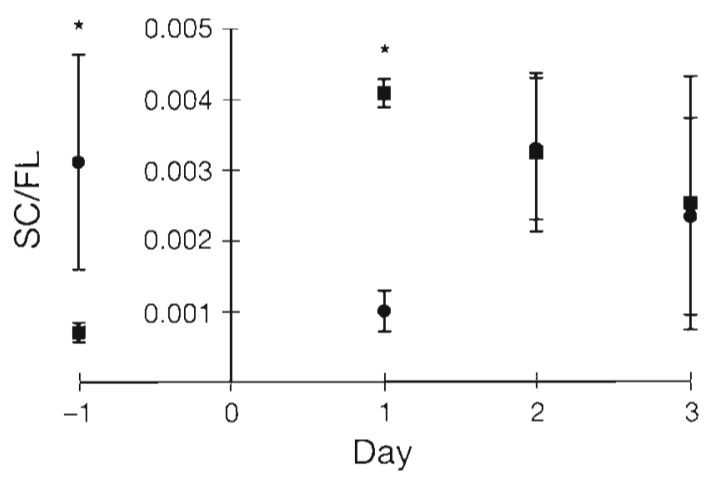

Fig. 3. Limanda limanda. Median \pm first quartile SC/FL index for the stomach contents of dab sampled from the treatment (ם) or control (-) areas at time intervals before and after creating the fishing disturbance. * Significant differences $(p<0.05)$

bance, the SC/FL index of dab collected on the treatment line had increased significantly since the previous day and was significantly higher than for dab collected on the control line (Fig. 3; K-W, H=7.29, p< 0.008 ). Thereafter, the SC/FL index did not vary significantly for dab collected from either treatment or control lines (Fig. 3).

Discussion. We have demonstrated elsewhere (Kaiser \& Spencer 1996a, Ramsay et al. 1996) that nontarget fish, in particular dab, and invertebrate species migrate into areas of the seabed that have been disturbed by trawling activity. Previous studies suggest that whiting, gurnards and hermit crabs increase their food intake in these areas (Kaiser \& Spencer 1994, Ramsay et al. 1996). However, in the present study, dab did not increase in abundance in the disturbed area compared with the control areas. The density of dab prior to disturbance was similar in both the present and Kaiser \& Spencer's (1996a) study (mean $\pm 95 \% \mathrm{CI}$ (confidence interval) per $1000 \mathrm{~m}^{2}: 12.6 \pm 2.2$, present study; $13.0 \pm 0.6$ Kaiser \& Spencer 1996a). Both studies were carried out in autumn; however, the habitats were different. The site examined in the present study is at a depth of $40 \mathrm{~m}$ in turbid water with little if any light penetration at the seabed, whereas Kaiser \& Spencer's (1996a) site was in shallower water (14 to $20 \mathrm{~m}$ ) with less turbidity. We have observed a similar difference in the pattern of response for other scavengers studied at these 2 sites (Ramsay et al. in press). The contrasting responses probably relate to differences in habitat characteristics (depth, turbidity, light and currents). Nevertheless our results indicate a marked increase in the intake of prey for fish sampled on the disturbed line (Fig. 2). While the species found in the diet did not vary, fish feeding on the disturbed line ate large numbers of the oral discs of Amphiura spp., whereas they would normally graze the arms which protrude from the sediment (Duineveld \& van 
Noort 1986). Our results suggest that as the tickler chains pass through surface layers of the sediment, they dig out or expose entire brittlestars increasing their susceptibility to predation by dab. This would explain the large increase in oral discs in the diets of dab. We believe this is the first study to demonstrate that dab increase their intake of food by feeding in areas disturbed by fishing activities. Fishing pressure in the North Sea has led to a decline in the populations of larger target species such as cod and plaice, whereas the relative abundance of smaller non-target species has increased (Greetstreet \& Hall 1996, Rijnsdorp et al. 1996). Dab remain the most abundant flatfish species in the North Sea, and their numbers have increased in certain areas (Heessen \& Daan 1996\}. Various explanations have been suggested for the changes observed in North Sea dab populations. Eutrophication in the coastal waters of the eastern North Sea has increased the biomass of benthic invertebrates which correlates with improved growth rates for small size-classes of plaice and sole (Rijnsdorp \& Leeuwen 1996). Offshore, in deeper water, a reduction in the abundance of larger size-classes of these fish has been linked to beam trawling effort (Millner \& Whiting 1996, Rijnsdorp \& Leeuwen 1996). Despite high bycatch mortality rates for dab (Kaiser \& Spencer 1995), their abundance has increased both in-and offshore. While increased abundances inshore may be linked to eutrophication effects as for plaice (Rijnsdorp \& Leeuwen 1996), the offshore increase may be related to fisheries activities.

The combined effects of predator and competitor removal, plus increased food availability resulting from eutrophicaton and trawling disturbance, may have contributed to the observed increases in dab abundance.

Acknowledgements. The reference to propnetary products in this paper should not be construed as an official endorsement of these products, nor is any criticism mplied of similar products which have not been mentioned. This research was partly funded by EC contract AIR 94 1664. We thank Haydn Hughes-Jones for help with sample processing.

This note was submitted to the editor

\section{LITERATURE CITED}

Daan N, Bromley PJ, Hislop JRG, Nielsen NA (1990) Ecology of North Sea fish. Neth J Sea Res 26:343-386

Dumeveld GCA, Künitzer A, Heyman RP (1987) Amphiura filiformis (Ophiuroidea: Echinodermata) in the North Sea. Distribution, present and former abundance and size composition. Neth J Sea Res 21:317-329

Duineveld GCA, van Noort GJ (1986) Observations on the population dynamics of Amphiura filiformis (Ophiuroidea: Echinodermata) in the southern North Sea and its exploitation by the dab, Limanda limanda. Neth J Sea Res 20:85-94

Greenstreet SPR, Hall SJ (1996) Fishing and the ground-fish assemblage structure in the north-western North Sea: an analysis of long-term and spatial trends. J Anim Ecol 65:577-598

Heessen HJL, Daan N (1996) Long-term trends in ten nontarget North Sea fish species. ICES J Mar Sci 53:1063-1078

Kaiser MJ, Spencer BE (1994) Fish scavenging behaviour in recently trawled areas. Mar Ecol Prog Ser 112:41-49

Kaiser MJ, Spencer BE (1995) Survival of by-catch from a beam trawl. Mar Ecol Prog Ser 126:31-38

Kaiser MJ, Spencer BE (1996a) Behavioural responses of scavengers to beam trawl disturbance. in: Gireenstreet SPR, Tasker ML (eds) Aquatic predators and their prey. Blackwell Scientific Publications, Oxford, p 117-123

Kaiser MJ, Spencer BE (1996b) The effects of beam-trawl disturbance on infaunal communities in different habitats J Anim Ecol 65:348-358

Lindley JA, Gamble JC. Hunt HG (1995) A change in the zooplankton of the central North Sea $\left(55^{\circ}\right.$ to $\left.58^{\circ} \mathrm{N}\right)$ : a possible consequence of changes in the benthos. Mar Ecol Prog Ser 119:299-303

Millner RS, Whiting CL (1996) Long-term changes in growth and population abundance of sole in the North Sea from 1940 to the preserat. ICES J Mar Sci 53:1185-1195

Ramsay K, Kaiser MJ, Hughes RN (1996) Changes in hermut crab feeding patterns in response to trawling disturbance. Mar Ecol Prog Ser 144:63-72

Ramsay K, Kaiser MJ, Moore PG. Hughes RN (in press) Consumption of fisheries discards by benthic scavengers utilisation of energy subsidies in different marine habitats. J Anim Ecol

Rijnsdorp AD, van Leeuwen PI (1996) Changes in growth of North Sea plaice since 1950 in relation to density, eutrophication, beam-trawl effort, and temperature. ICES J Mar Sci 53:1199-1213

Rijnsdorp AD, van Leeuwen PI, Daan N, Heessen HJL (1996] Changes in abundance of demersal fish species in the North Sea between 1906-1909 and 1990-1995. ICES J Mar SC1 53:1054-1062

Rijnsdorp AD, Vethaak AD, van Leeuwen PI (1992) Population biology of dab Limanda limanda in the south-eastern North Sea. Mar Ecol Prog Ser 91:19-35

Manuscript first received: February 20, 1997

Revised version accepted: April 11, 1997 